\title{
38. Terraces of the South Sea Islands under the Japanese Mandate.
}

\author{
By Risaburo Tayama.
}

(Comm. by H. YABE, M.I.A., May 12, 1939.)

\begin{abstract}
All of the South Sea Islands under the Japanese Mandate are terraced in different degree of development, with flat surfaces at different heights. The terraces are most numerous and best developed on Rota island of the South Mariana group, where 16 of them can be counted. These flat surfaces on the islands of the South Mariana group are the surfaces mostly of coral reefs, while the higher ones of flat surfaces of the islands of the East Caroline group are the surfaces of basalt flow ; in the following consideration the latter category is excluded.

The correlation of these terraces on different islands is by no means difficult by taking their respective heights into account, provided with that these islands are situated on the same submarine ridge, while the work is of considerable risk in the case of their belonging to different submarine ridges. However it is found on all these islands that there is a terrace or a group of terraces built of an elevated coral reef limestone of Plio-Pleistocene age,- - the Mariana and Palau limestone of the Mariana and Palau group respectively, all of which are proven on petrological and palaeontological characteristics and similar physiographical feature to belong to the same geological age; it follows then that the heights of the deposition surfaces of the limestone on different islands should be taken as the chief criteria for the correlation of the other terraces of higher and lower position with one another on these islands.
\end{abstract}

From the respective heights of the Mariana-Palau limestone and from the distribution as well as the amount of dissection of all the terraces, the writer has correlated the terraces of each respective island and arranged them into four groups. Before going further into explanation, the general order of succession of different geological formations distributed in these islands will first be given as follows:

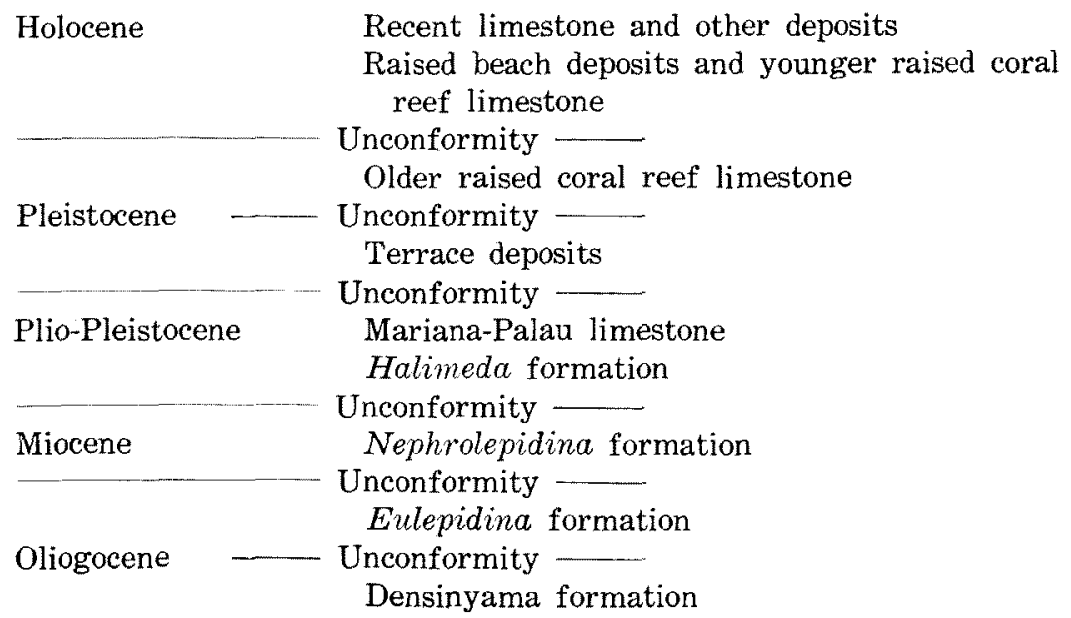




Enconformity
Camerina formation
Pre-Tertiary
Unconformity
Pre-Tertiary formation

The four groups of terraces are:

Pre-Mariana terraces (PM). This comprises three terraces which were built prior to the deposition of the Mariana-Palau limestone. $\mathrm{PM}_{1}$ and $\mathrm{PM}_{2}$ are distinguished as being the deposition surfaces of the Nephrolepidina formation, while $\mathrm{PM}_{3}$ which cuts the Nephrolepidina formation, is the deposition surface of the Halimeda formation.

Mariana terrace (M). This is the surface of the elevated coral reef limestone (Mariana-Palau limestone) of Plio-Pleistocene age, and according to its different heights, it is divisible into $\mathrm{M}_{1}, \mathrm{M}_{2}$, and $\mathrm{M}_{3}$.

Pelilieu terrace (P). This is the surface of the older raised coral reef limestone, the typical example of which is the Pililieu limestone of Pelilieu, Palau islands.

Post-Pelilieu terrace (PP). This is the surface of the younger raised coral reef limestone.

Of the above mentioned terraces, $\mathrm{PM}_{1}$ and $\mathrm{PM}_{2}$ are confined in their distribution to Saipan islands of the South Mariana group, $\mathbf{P M}_{3}$ is distributed with nearly equal development on the western island groups (South Mariana, Palau and Yap) and some of the eastern groups (East Carolines). Both $\mathrm{M}$ and $\mathrm{P}$ terraces are developed chiefly in the western island groups except for the rare occurrence on Fais islands of the West Carolines; all these have not been found elsewhere. The PP terrace is developed to nearly equal degree on all the islands, and attains about 1-2 $\mathrm{m}$ above the reef-flat.

$\mathrm{PM}, \mathrm{M}$ and $\mathrm{P}$ terraces as shown in the annexed table, are developed in different heights among the different islands, thus by measuring their respective differences in height, the amount of crustal movement can approximately be estimated. That the PP terrace is developed on all of these islands, affords good opportunity to study the recent lowering of sea level.

In the South Mariana group where terraces are very well developed and drowned valleys have not been detected, the sea-level-coral-reef shows the morphological features of apron-reef, fringing-reef and very poor almost barrier reef. Contrary, in the East Caroline group where terraces are very poorly developed, drowned valleys have been discovered in good development, and the sea-level-coral-reef shows the morphological features of almost barrier reef, barrier reef and almost atoll.

From the foregoing lines, it is recognized that a very close relationship exists between the development of the coral reefs and crustal movement. 
No. 5.] Terraces of the South Sea Islands under the Japanese Mandate.

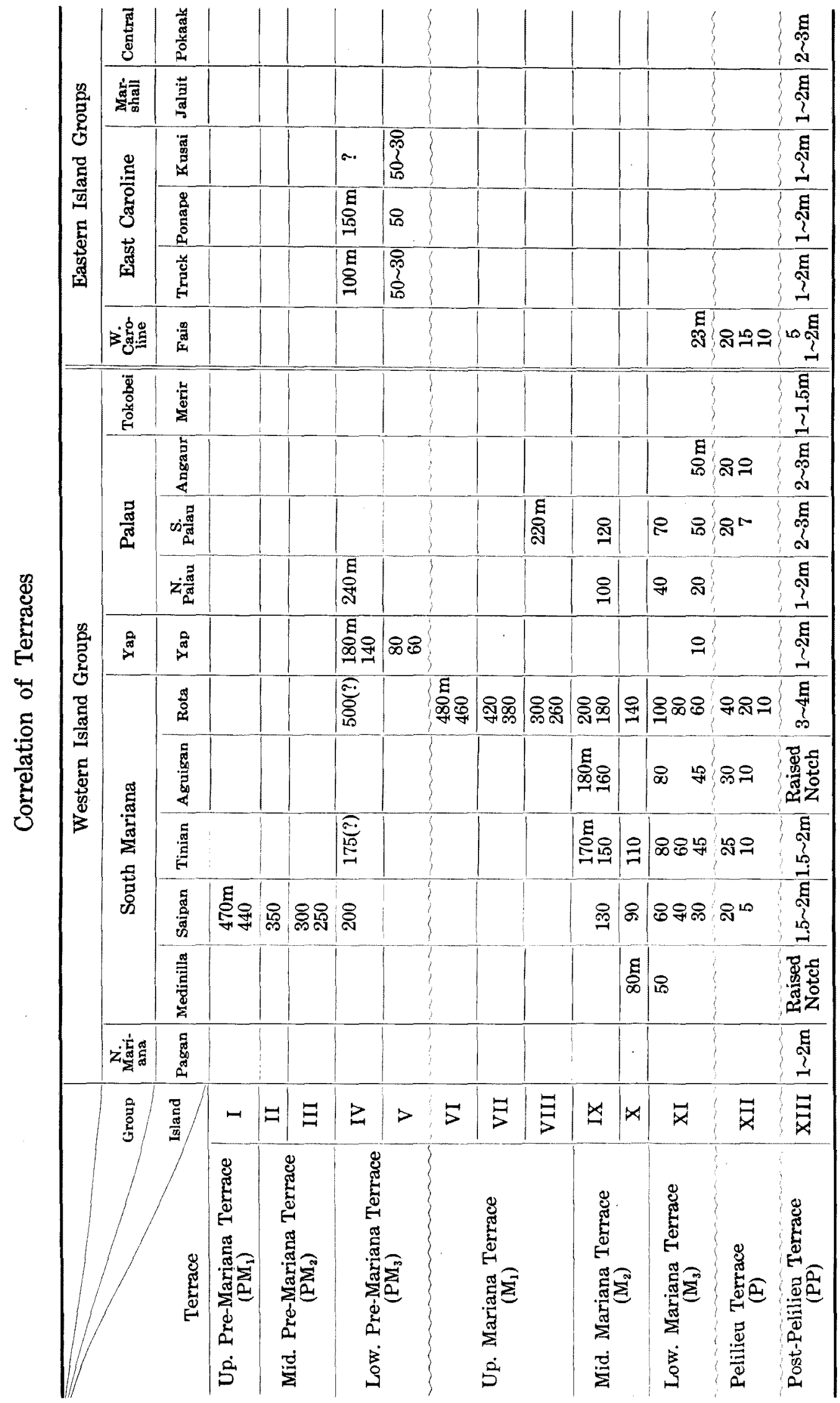

